\title{
Effect of experimental folate deficiency on lipid metabolism in liver and brain
}

\author{
By B. ÅKESSON, C. FEHLING, M. JÄGERSTAD AND U.STENRAM \\ Department of Clinical Chemistry, Department of Neurology, Department of Nutrition \\ and Department of Pathology, University of Lund, Lund, Sweden
}

(Received 24 September 1981 - Accepted 17 November 1981)

1. Rats were given a purified folate-deficient diet containing $5 \mathrm{~g}$ succinylsulphathiazole $/ \mathrm{kg}$ for $4-5 \mathrm{months}$ in two experiments. Control rats were supplemented with folic acid in the drinking-water.

2. Weight gain was much below normal in the folate-deprived rats after the first month. Very low folate levels were recorded in blood, liver and peripheral nerve (12-33\% of control). In the central nervous system, including the cerebrospinal fiuid, the folate depletion was less conspicuous ( $50-80 \%$ of control). Only marginal signs of anaemia were found and no signs of neurological dysfunction were detected, using nerve conduction velocity measurement and co-ordination tests.

3. Light and electron microscopy of the folate deficient liver revealed fatty infiltration, and enlargement of liver parenchymal cells, nuclei and nucleoli. There was often a considerable amount of bile ductular cells in the lobuli but no cirrhosis. The morphological changes resembled those observed in choline deficiency.

4. Phospholipid N-methylation in liver was depressed in folate deficiency. This was probably due to a decreased availability of S-adenosylmethionine caused by the low concentrations of methylated folate in liver. Intraperitoneal administration of methionine did not normalize phospholipid methylation.

5. In folate deficiency the proportion of ethanolamine phosphoglyceride in liver was increased at the expense of choline phosphoglyceride, which is consistent with a decreased phospholipid methylation. Also an increase in liver triacylglycerol was noted, in accordance with the morphological observations. Brain lipid composition was unchanged.

6. After the injection of labelled ethanolamine, isotope accumulated in liver phosphoethanolamine in folate deficiency, probably due to an impairment of the CTP: ethanolaminephosphate cytidylyltransferase $(E C 2.7 .7 .14)$ reaction. The mechanism of this impairment is discussed.

7. Although the low concentrations of folate was the main nutritional change in the deprived animals, changes with respect to vitamin $B_{12}$ and maybe also choline cannot be excluded. We conclude that some of the changes in folate deficiency, i.e. fatty liver and decreased biosynthesis of liver phospholipids may be due to a precipitated deficiency of lipotropic agents, whereas other differences may be specific for deficiency of folate per se, such as changes in liver phospholipid fatty acids and some of the morphological aberrations.

Folate and vitamin $\mathbf{B}_{12}$ are intimately connected in the methylation of homocysteine to methionine and S-adenosylmethionine (AdoMet), one of the most important methyl-group donors in mammals (Fig. 1). A substantial proportion of the methyl groups of liver methionine is utilized via AdoMet for phospholipid N-methylation (Fig. 1). The rate of this reaction in the hepatocyte is influenced by the availability of methionine-AdoMet (Sundler \& Åkesson, 1975) and ethanolamine phosphoglyceride (EPG; Åkesson, 1978). Earlier work has demonstrated a decrease of the formation of choline phosphoglyceride (CPG) from EPG in livers and hepatocytes from vitamin $B_{12}$-deficient rats ( $\AA$ kesson et al. 1978, 1979; Jägerstad et al. 1980). This was probably due to depressed activity of the vitamin $\mathrm{B}_{12}$-dependent enzyme tetrahydropteroylglutamate methyltransferase (EC2.1.1.13) in the vitamin $B_{12}$-deficient animals, which would reduce the availability of AdoMet. If so, folate deficiency would be expected to give rise to the same changes of phospholipid metabolism in the absence of vitamin $B_{12}$ deficiency (Fig. 1).

Vitamin $B_{12}$ deficiency is a well-known cause of damage to the central and peripheral nervous system in man. Evidence is accumulating that folic acid deficiency could give rise to similar changes (Melamed, 1979). We have previously demonstrated neurological impairment in vitamin $B_{12}$-deficient rats (Fehling et al. 1978). The chemical mechanism of 


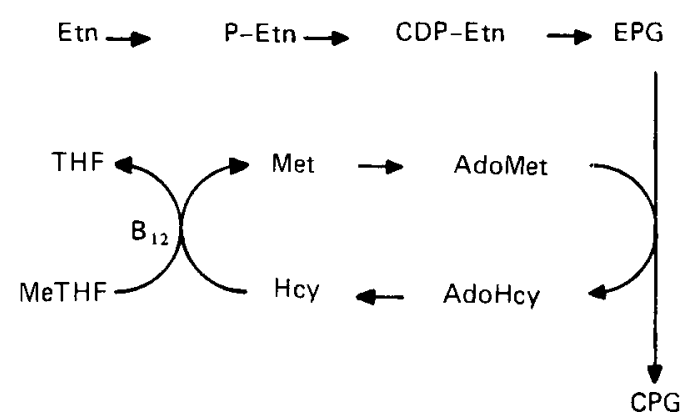

Fig. 1. Metabolic relationship between folates and phospholipid biosynthesis. MeTHF, methyltetrahydrofolate; Met, methionine; Hcy, homocysteine; Ado, adenosyl; Etn, ethanolamine; EPG, ethanolamine phosphoglyceride, CPG, choline phosphoglyceride.

the damage to the nervous system is obscure. One possibility is that it occurs as a consequence of the depressed formation of AdoMet, as recently suggested (Fehling \& Jägerstad, 1979). In this instance the same neurological impairment should appear in folate-deficient rats, provided these showed biochemical signs of impaired methylation.

The present study was undertaken to elucidate the previously mentioned issues by raising folate-deficient rats, examining their lipid metabolism with emphasis on phospholipid methylation, and correlating the biochemical changes with histological findings in the liver and neurological status.

\section{METHODS}

Animals

Each of two series (A and B) of male Wistar rats, weighing approximately $170 \mathrm{~g}$ were randomly divided into a control and an experimental group with twelve animals in each group. All animals were reared on the same folate-deficient diet for 4-5 months. The control rats were supplemented with folic acid in the drinking-water $(0.5 \mathrm{mg} / \mathrm{l})$. All animals had free access to food and water and were housed under identical conditions in stainless-steel wire-net cages with elevated mesh floors minimizing coprophagy. The cages measured $560 \times 310 \times 200 \mathrm{~mm}$ and twelve rats were initially housed in each cage. Body-weights were recorded monthly or sometimes weekly.

\section{Diet}

A purified diet was prepared, consisting of $(\mathrm{g} / \mathrm{kg})$ : sucrose 220 , starch 450 , casein 200 (purified powder; Sigma), soya-bean oil 55, vitamin mixture 20, mineral mixture 50, succinylsulphathiazole 5 (Sigma). Vitamins added were $(\mathrm{mg} / \mathrm{kg}$ diet): retinylpalmitate $1 \cdot 7$, ergocalcipherol $0.04, \alpha$-tocopheryl acetate 150 , menadione 5 , thiamine 5 , riboflavin 5 , nicotinic acid 20, calcium pantothenate 10 , pyridoxine hydrochloride 10 , cyanocobalamin 0.01 , biotin 0.5 , inositol 100 , choline 500 . The amounts of minerals added were $(\mathrm{mg} / \mathrm{kg} \mathrm{diet})$ : calcium 8125 , phosphorus 5670 , potassium 6270 , sodium 1180 , chloride 1820 , magnesium 950 , iron 185 , manganese 110 , zinc 25 , copper 5 , iodine $0 \cdot 4$, chromium $0 \cdot 2$, molybdenum $0 \cdot 2$, selenium 0.07 . The concentration of folic acid was determined microbiologically to be on the average $50 \mu \mathrm{g} / \mathrm{kg}$ diet.

\section{Isotope experiment}

All rats in Expt A received $2 \mu \mathrm{Ci}\left[{ }^{14} \mathrm{C}\right]$ ethanolamine $(44 \mathrm{mCi} / \mathrm{mmol}$; Radiochemical Centre, Amersham, Bucks., UK) administered intraperitoneally in $2 \mathrm{ml} 0.15 \mathrm{M}$-sodium chloride $2 \mathrm{~h}$ before death. Half the animals in both the control and experimental groups received in addition $60 \mathrm{mg} \mathrm{L}$-methionine dissolved in the same solution. The rats were fasted for $24 \mathrm{~h}$ 
before death. In Expt $\mathrm{B}, 10 \mu \mathrm{Ci}\left[{ }^{3} \mathrm{H}\right]$ ethanolamine $(24 \mathrm{Ci} / \mathrm{mmol})$ and $60 \mathrm{mg} \mathrm{L}$-methionine in $2 \mathrm{ml} 0.15 \mathrm{M}$-sodium chloride was injected $2 \mathrm{~h}$ before death to all animals.

\section{Preparations of tissues and analyses of vitamins}

The rats were killed by aortic puncture under diethyl ether anaesthesia. Blood was collected in heparinized tubes and part of it was centrifuged to separate plasma. Cerebrospinal fluid was collected by cisternal puncture. Fluids were frozen in tubes containing ascorbic acid $(5 \mathrm{mg} / \mathrm{ml})$ to prevent oxidation of folate and stored in the dark at $-17^{\circ}$ until assayed.

The liver and part of the nervous system were rapidly excised, weighed and frozen in liquid nitrogen, except pieces of liver immersed in fixatives for morphological examination. Tissues were stored in the dark in sealed plastic bags at $-80^{\circ}$ until assayed. The analyses of folic acid and vitamin $B_{12}$ concentrations were performed microbiologically, as described earlier (Fehling \& Jägerstad, 1978). Standard curves were also made up for Lactobacillus casei, Streptococcus faecalis and Euglena gracilis with and without succinylsulphathiazole or sulphathiazole in concentrations corresponding to those found in our experiments (see p. 509). These concentrations did not interfere with the growth of any of the used microorganisms. Haemoglobin was determined as cyanmethaemoglobin, and packed cell volume using a micro-haematocrite procedure.

\section{Lipid analysis}

Lipids from liver and brain were extracted, separated by thin-layer chromatography and analysed for radioactivity, phosphorus and fatty acid composition as described previously ( $\AA$ kesson et al. 1979). Triacylglycerol:phospholipid values were determined by thin-layer chromatography-flame ionization detection using an Iatroscan TH Analyser (NewmanHowells Assoc. Ltd, Stockbridge, Hants, UK), essentially according to Sipos \& Ackman (1978). Duplicate analyses on Chromarods were performed routinely.

\section{Analysis of water-soluble ethanolamine compounds}

The tissue residue remaining after lipid extraction was extracted with ethanol-water $(1: 4$, v/v) as described previously (Sundler et al. 1972; Sundler, 1973). The extract was combined with the washings of the lipid extract and analysed by ion-exchange column chromatography on AG1-X4 (formate). Ethanolamine and phosphoethanolamine were isolated as described by Sundler (1973). The identity of the compounds was further substantiated using thin-layer chromatography with ethanol $-20 \mathrm{ml} \mathrm{NH}_{4} \mathrm{OH} / 1(1: 2, \mathrm{v} / \mathrm{v})$ as developing solvent (Sundler, 1975). Other ethanolamine-containing compounds were not isolated.

\section{Sulphonamides}

Plasma from seven control rats, from three folate-deficient rats and from three supplemented deficient rats in the second series was examined according to Bretton and Marshall (Annino, 1961). After extraction with trichloracetic acid $(50 \mathrm{~g} / \mathrm{l})$, five, four and three livers from the control, folate-deficient and supplemented deficient groups respectively were analysed by the same method.

\section{Morphological investigation}

For light microscopy, liver slices were fixed in formaldehyde $(40 \mathrm{ml} / 1)$, embedded in paraffin and stained with haematoxylin-erythrosine, van Gieson, and the Turnbull blue reaction for iron pigment.

For electron microscopy, slices were fixed in $20 \mathrm{ml}$ glutaraldehyde $/ 10.1 \mathrm{M}$-cacodylate buffer and $0 \cdot 1 \mathrm{M}$-sucrose, $\mathrm{pH} 7 \cdot 2$, at $+4^{\circ}$ for $4 \mathrm{~h}$ with post-fixation in $20 \mathrm{ml} \mathrm{OsO} / 1$ $0.1 \mathrm{M}-s$-collidine buffer, $\mathrm{pH} 7 \cdot 4$, at $+4^{\circ}$ for $1 \mathrm{~h}$, embedded in Epon. Sections were contrasted with uranyl acetate-lead citrate and examined in a Zeiss EM 10 electron microscope. 


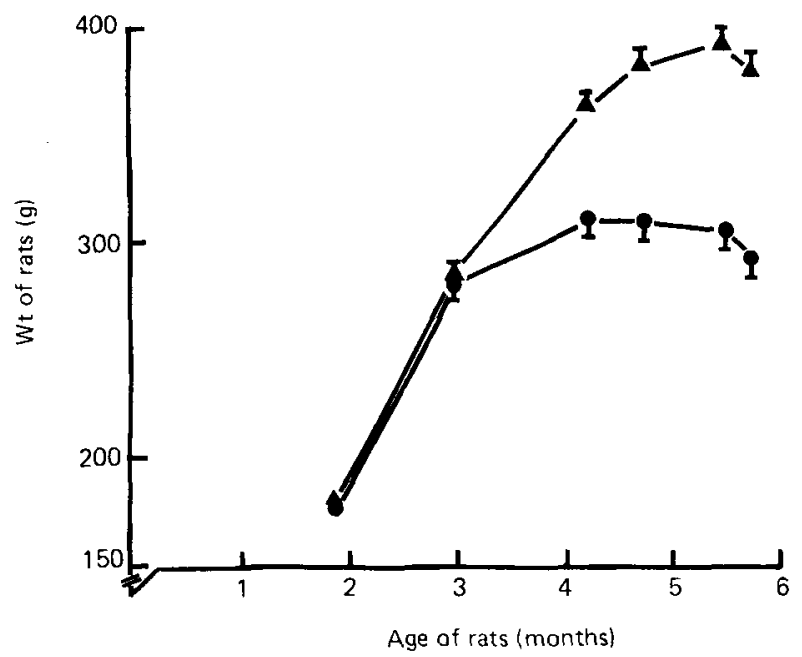

Fig. 2. Expt A. Growth curves of folate-deficient ( $)$ and supplemented ( $\mathbf{A}$ ) rats. Points are mean values, with standard errors represented by vertical bars. For details of animals and diet, see p. 506 .

\section{Neurological examinations}

Tests of co-ordination measured the animals' ability to stay on a tilted steel platform and to strike the ground with their feet first after being somersaulted. Motor nerve conduction velocity was measured in the tail, the termperature of which was adjusted to $37^{\circ}$ by a warm-air fan (Fehling et al. 1975).

\section{RESULTS}

Survival and body-weights

The rats of Expt A were killed after 4 months. In the folate-deficient groups three of twelve rats died spontaneously. The growth curves demonstrate significant differences between the groups already after 10 weeks $(P<0.001)$, and the differences increased with time (Fig. 2).

In Expt B one control rat and two folate-deficient rats died spontaneously. After 13 weeks five folate-deficient rats with decreasing body-weights were moved to another cage and were supplemented with folic acid in their drinking-water $(1 \mathrm{mg} / 1)$ in order to prevent further losses. These animals will be referred to as supplemented deficient rats. The body-weights in both the folate-deficient group and the supplemented deficient group increased thereafter (Fig. 3), and no more rats died.

\section{Vitamin and blood status}

Table 1 shows the concentrations of total and methylated folate in both experiments. The injection of methionine to half the animals in Expt $A$ had no effect on total folate and methylated folate concentrations and therefore values from both groups of rats were pooled. The folate-deficient rats had lower folate concentrations in Expt A than in Expt B. The folate levels in liver and blood of the deficient animals were $12-33 \%$ of control values whereas, in the central nervous system, the folate concentrations were $50-80 \%$ of the control values. The folate concentrations of the peripheral nerves decreased in parallel to those of the liver and blood. Methylated folate was decreased in parallel to total folate resulting in an essentially unchanged proportion of methylated folate from total folate in the deficient rats compared with the supplemented rats.

Despite the supplementation of the diet with vitamin $B_{12}$, the levels of vitamin $B_{12}$ found in the rats were generally low, especially in Expt $B$ and the levels were lowest in the folate-deficient animals (Table 2). 


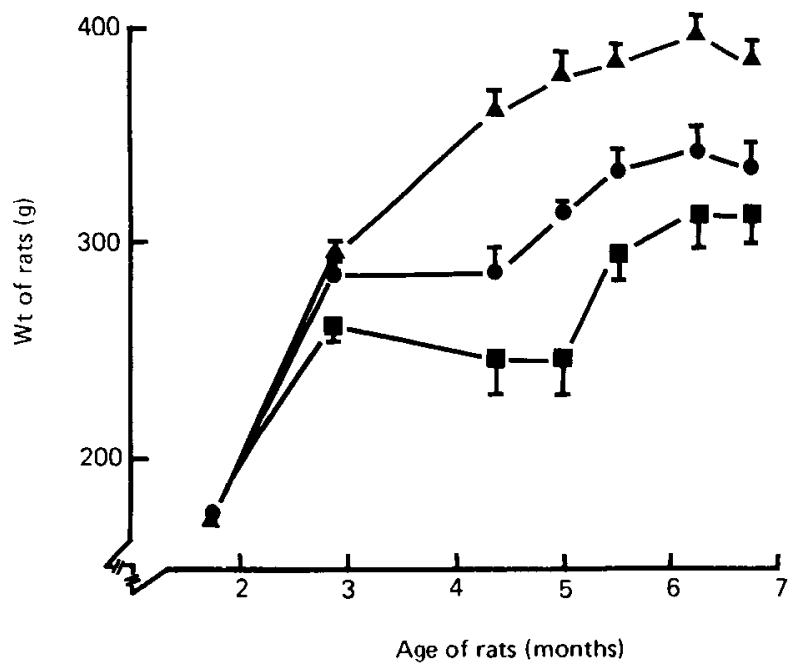

Fig. 3. Expt B. Growth curves of folate-deficient ( $O$ ), supplemented (A), and supplemented deficient (E) rats. The last group was supplemented after 5 months. Points are mean values, 1 SE represented by vertical bars. For details of animals and diet, see p. 506.

Only marginal signs of anaemia were found in the folate deficient animals of Expt $\mathrm{A}$, where the mean haemoglobin concentration $(\mathrm{g} / \mathrm{l})$ was $130 \pm 8$ (mean $\pm \mathrm{SE}$ ) as compared to $160 \pm 3$ in the folate supplemented animals $(P<0 \cdot 01)$. The corresponding values for packed cell volumes were $41 \cdot 0 \pm 2 \cdot 7$ and $47 \cdot 5 \pm 0 \cdot 7(P<0 \cdot 05)$.

\section{Sulphonamide concentrations}

The mean $( \pm \mathrm{SE})$ plasma concentration $(\mu \mathrm{mol} / 1)$ of sulphonamide was $106 \pm 10(n 7)$ in the supplemented rats, $137 \pm 26(n 3)$ in the folate-deficient, and $148 \pm 11(n 3)$ in the supplemented deficient group. The last concentration was significantly different from that of the supplemented rats $(P<0.05)$. The mean $( \pm$ SE) sulphonamide concentration $(\mathrm{nmol} / \mathrm{g})$ in the livers of the folate-supplemented rats was $20 \pm 0 \cdot 8(n=5)$. The folate-deficient and supplemented-deficient rats had mean concentrations that did not differ significantly from that of the supplemented rats.

\section{Liver weight and composition}

The weights of the livers were approximately the same in the supplemented and the folate-deficient animals. Since the latter had substantially lower body-weights a significant relative hepatomegaly could be demonstrated in both series of folate-deficient rats when liver size was calculated as a percentage of body-weight (Table 2). In folate deficiency, total liver lipid increased, most clearly demonstrated in Expt B (Fig. 4). The proportion of triacylglycerol relative to phospholipid in lipid extracts was measured by thin-layer chromatography-flame ionization detection. The triacylglycerol:phospholipid value was increased in folate deficiency, and again the differences were more pronounced in Expt B (Table 3). Since the amount of liver phospholipids was only approximately $20 \%$ lower in folate deficiency, it can be concluded that triacylglycerol was the main lipid accumulating in folate deficiency. For changes in phospholipid composition, see p. 512.

\section{Biosynthesis and composition of liver phospholipids}

The changes in phospholipid metabolism in folate deficiency was followed by analysis of radioactivity in different compounds after the injection of labelled ethanolamine. In folate deficiency the incorporation of labelled ethanolamine into total liver lipids was depressed, 
B. ÅKESSON AND OTHERS

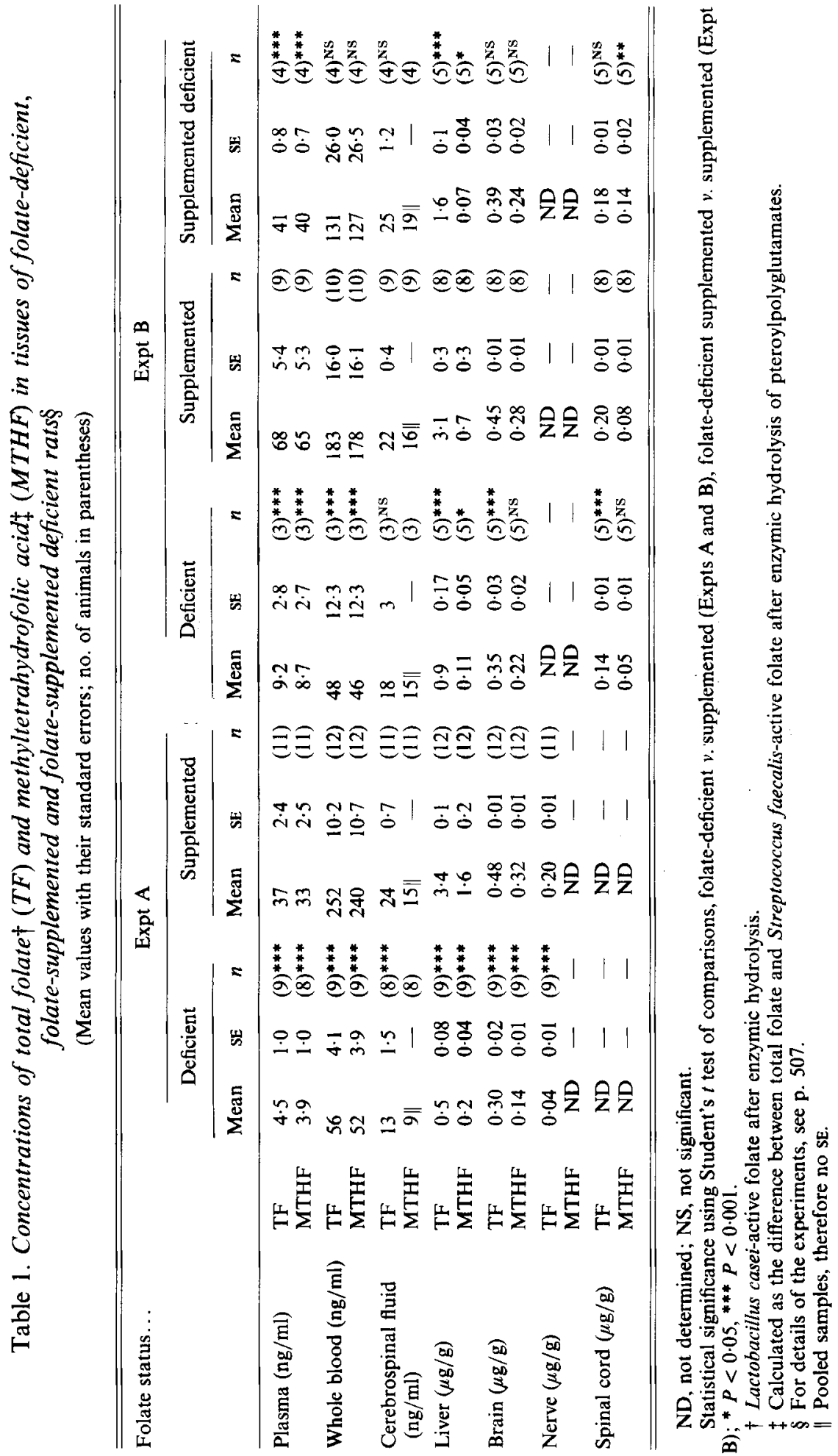


Table 2. Weights $(\%$ body-weight $)$ and vitamin $B_{12}$ concentrations $(\mathrm{ng} / \mathrm{g}$ wet weight $)$ of livers from folate-deficient, supplemented and supplemented deficient rats

(Mean values with their standard errors; no. of animals in parentheses)

\begin{tabular}{|c|c|c|c|c|c|c|c|c|c|}
\hline \multirow[t]{2}{*}{ Folate status... } & \multicolumn{3}{|c|}{ Deficient } & \multicolumn{3}{|c|}{ Supplemented } & \multicolumn{3}{|c|}{ Supplemented deficient } \\
\hline & Mean & SE & $n$ & Mean & SE & $n$ & Mean & SE & $n$ \\
\hline \multicolumn{10}{|l|}{ Expt A } \\
\hline $\mathrm{Wt}$ & 3.67 & 0.25 & (9) & $2 \cdot 78 \dagger$ & 0.08 & (12) & & & \\
\hline Vitamin $\mathbf{B}_{\mathbf{1 2}}$ & 24 & 5 & (12) & & $4 \cdot 7$ & (9) & & & \\
\hline \multicolumn{10}{|l|}{ Expt B } \\
\hline $\mathbf{W t}$ & $3 \cdot 12$ & 0.12 & (4) & $2.87 \dagger$ & 0.07 & (8) & $3 \cdot 31$ & 0.09 & (5) \\
\hline Vitamin $\mathbf{B}_{12}$ & 18 & $2 \cdot 6$ & (5) & $23 \ddagger$ & 1.9 & (8) & $13^{*}$ & 0.9 & (5) \\
\hline
\end{tabular}

* Supplemented-deficient $v$. deficient; $P<0.01$.

$\dagger$ Folate-supplemented v. deficient; $P<0.001$.

† Folate-supplemented $v$. supplemented deficient; $P<0.001$.

Statistical analysis using Student's $t$ test.

For details of diet, see p. 506.

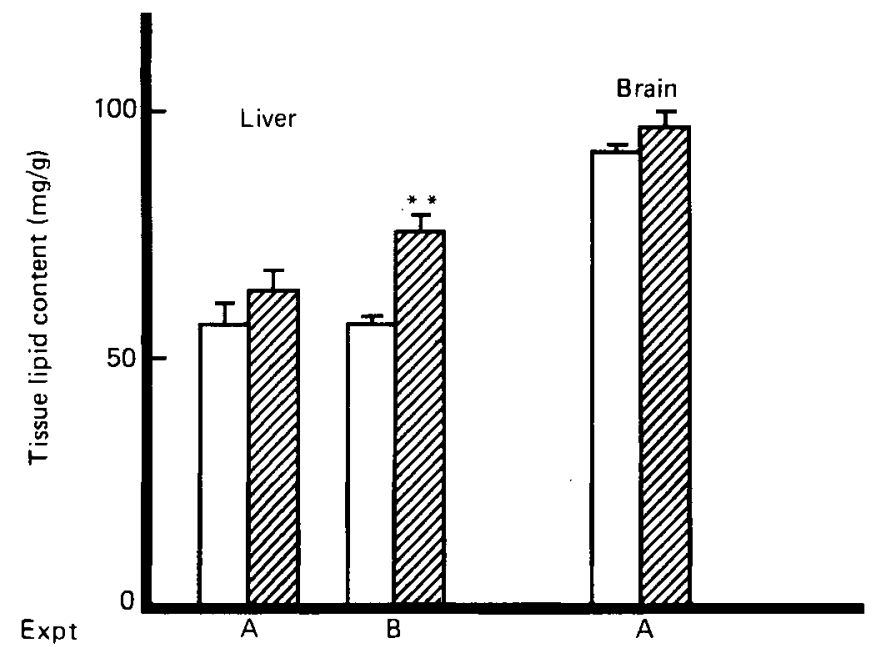

Fig. 4. Tissue lipid content (mg/g) in liver and brain of folate-deficient ( $B$ ) or supplemented ( $\square$ ) rats. Values are means with their standard errors for three to six rats/group. The difference between groups was statistically significantly different: ${ }^{* *} P<0 \cdot 01$.

whereas the radioactivity in water-soluble compounds increased severalfold in both experiments (Table 4). This may indicate an impairment of the conversion of phosphoethanolamine or CDP-ethanolamine or both to EPG. Analysis of total water-soluble labelled compounds in Expt B showed that phosphoethanolamine radioactivity was markedly increased in folate deficiency (Fig. 5). The amount of radioactivity in CDP-ethanolamine was too low to permit accurate determination of levels. There was no major change in total liver radioactivity in folate deficiency, indicating that liver uptake of ethanolamine was unaffected.

Phospholipid methylation was determined from the proportion of liver lipid radioactivity recovered in CPG, after the injection of labelled ethanolamine (Table 5). In folate deficiency, phospholipid methylation was depressed irrespective of whether the animals had received methionine or not. Administration of methionine increased phospholipid methylation in 
Table 3. Relative amounts of triacylglycerol and phospholipids in livers of folate-deficient rats

(Mean values with their standard errors; no. of animals in parentheses)

\begin{tabular}{|c|c|c|c|c|c|c|c|}
\hline \multirow[t]{2}{*}{ Folate status... } & \multirow[b]{2}{*}{ Methionine } & \multicolumn{3}{|c|}{ Deficient } & \multicolumn{3}{|c|}{ Supplemented } \\
\hline & & Mean & $\mathbf{S E}$ & $n$ & Mean & SE & $n$ \\
\hline \multicolumn{8}{|l|}{ Expt A } \\
\hline TG:PL & + & 0.68 & $0 \cdot 19$ & (4) & 0.37 & 0.06 & (6) \\
\hline & - & 0.50 & 0.07 & (5) & 0.35 & 0.07 & (6) \\
\hline \multicolumn{8}{|l|}{ Expt B } \\
\hline TG:PL & + & $0.93^{* * *}$ & 0.02 & (3) & $0 \cdot 22$ & $0 \cdot 04$ & (3) \\
\hline \multicolumn{8}{|l|}{ Expt B } \\
\hline $\begin{array}{l}\text { Total } \\
\text { phospholipids } \\
(\mu \mathrm{mol} / \mathrm{g})\end{array}$ & + & $38 \cdot 3^{*}$ & $3 \cdot 1$ & (3) & $50 \cdot 3$ & $2 \cdot 6$ & (3) \\
\hline
\end{tabular}

,+ Present; -, absent.

TG:PL, triacylglycerol:phospholipid (determined by thin-layer chromatography-flame ionization detection). Statistical significance of difference between groups: ${ }^{*} P<0.05,{ }^{* * *} P<0.001$ ( $t$ test).

Table 4. Incorporation of radioactivity from injected labelled ethanolamine into different liver metabolites in folate-deficient rats $(\%$ administered isotope $/ g$ liver $) \ddagger$

(Mean values with their standard errors; no. of animals in parentheses)

\begin{tabular}{|c|c|c|c|c|c|c|c|}
\hline & \multirow[b]{2}{*}{ Methionine } & \multicolumn{3}{|c|}{ Total lipids } & \multicolumn{2}{|c|}{$\begin{array}{l}\text { Methanol-water } \\
\text { phase }\end{array}$} & \multirow{2}{*}{$\begin{array}{c}\begin{array}{c}\text { Total } \\
\text { water-soluble } \\
\text { metabolites }\end{array} \\
\text { Mean }\end{array}$} \\
\hline & & $n$ & Mean & SE & Mean & SE & \\
\hline \multicolumn{8}{|l|}{ Expt A } \\
\hline \multirow[t]{2}{*}{ Folate-deficient } & + & (4) & 1.37 & $0 \cdot 36$ & $0.55+$ & $0 \cdot 17$ & $1 \cdot 15$ \\
\hline & - & (5) & 0.89 & 0.09 & $0.43^{\dagger}$ & $0 \cdot 10$ & 0.96 \\
\hline \multirow[t]{2}{*}{ Folate-supplemented } & + & (6) & $2 \cdot 20$ & $0 \cdot 21$ & $0 \cdot 19$ & 0.02 & $0 \cdot 38$ \\
\hline & - & (6) & $1 \cdot 32^{*}$ & 0.24 & $0 \cdot 16$ & 0.02 & $0 \cdot 30$ \\
\hline \multicolumn{8}{|l|}{ Expt B } \\
\hline Folate-deficient & + & (3) & 0.87 & 0.33 & $0 \cdot 26+\dagger$ & 0.02 & $1 \cdot 34$ \\
\hline Folate-supplemented & + & (3) & $2 \cdot 35$ & 0.42 & $0 \cdot 11$ & $0 \cdot 02$ & $0 \cdot 20$ \\
\hline
\end{tabular}

,+ Present; - , absent.

Significantly different from the corresponding group injected with methionine $(t$ test $\left.):^{*} P<0.05\right)$.

Significantly different from the corresponding supplemented group: $\dagger P<0.05$, $\dagger \dagger P<0.01$.

$\ddagger$ For experimental details, see p. 507.

control rats but not in folate-deficient rats. The decrease in phospholipid methylation was accompanied by changes in phospholipid composition and phospholipid fatty acid composition. In folate-deficient animals the proportion of liver EPG increased at the expense of CPG (Table 6), which can be explained by the impaired phospholipid methylation. In both phospholipids stearic acid increased in folate deficiency, mainly at the expense of palmitic acid (Fig. 6). In CPG docosahexaenoic acid decreased in folate deficiency. 


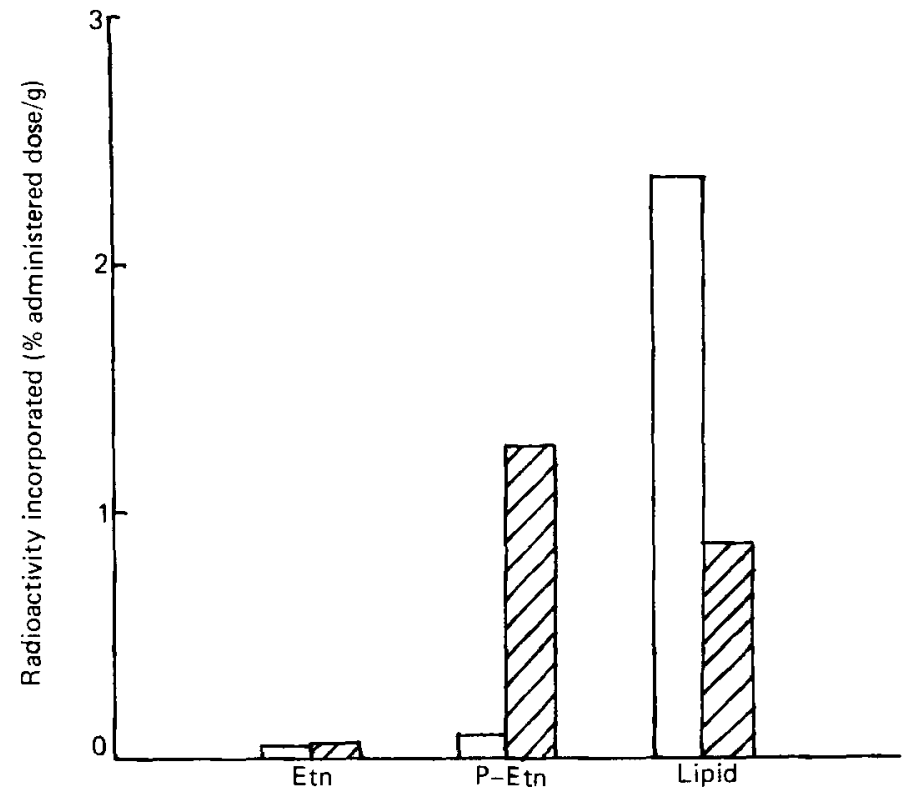

Fig. 5. Expt B. Incorporation of radioactivity from $\left[{ }^{3} \mathrm{H}\right]$ ethanolamine into ethanolamine-containing compounds in liver $(\%$ administered isotope $/ g$ liver) of folate deficient (6) or supplemented ( $\square$ ) rats. Values are means for three animals/group. Etn, ethanolamine; P-Etn, phosphoethanolamine. Etn and P-Etn were determined using a pooled sample as described on p. 507.

Table 5. Phospholipid methylation in livers of rats deprived of or supplemented with folate (\% liver lipid radioactivity in choline phosphoglyceride $) \ddagger$

(Mean values with their standard errors; no. of animals in parentheses)

\begin{tabular}{|c|c|c|c|c|c|c|c|c|c|c|c|c|}
\hline \multirow{3}{*}{$\begin{array}{l}\text { Folate status... } \\
\text { Methionine... }\end{array}$} & \multicolumn{6}{|c|}{ Deficient } & \multicolumn{6}{|c|}{ Supplemented } \\
\hline & \multicolumn{3}{|c|}{+} & \multicolumn{3}{|c|}{-} & \multicolumn{3}{|c|}{+} & \multicolumn{3}{|c|}{-} \\
\hline & Mean & $\mathrm{SE}$ & $n$ & Mean & SE & $n$ & Mean & $\mathbf{S E}$ & $n$ & Mean & $\mathrm{SE}$ & $n$ \\
\hline Expt A & $5 \cdot 9 * *$ & $2 \cdot 0$ & (4) & $5 \cdot 6+t$ & 0.5 & (5) & $13 \cdot 3$ & $0 \cdot 8$ & (6) & $8 \cdot 6^{* * *}$ & 0.5 & (6) \\
\hline Expt B & $5 \cdot 7^{* *}$ & $1 \cdot 4$ & (3) & - & & & $15 \cdot 1$ & 0.7 & (3) & - & & \\
\hline
\end{tabular}

Significantly different from supplemented group injected with methionine: ${ }^{* *} P<0.01,{ }^{* * *} P<0.001$.

Significantly different from supplemented group without methionine: $+\dagger P<0.01$.

$\ddagger$ Labelled ethanolamine and, where indicated, methionine were injected intraperitoneally $2 \mathrm{~h}$ before slaughter.

\section{Brain lipid composition}

Although phospholipid methylation is most active in the liver, it occurs also in other organs such as the brain (Hoffman et al. 1979; Crews et al. 1980). In folate deficiency no changes in total brain lipids (Fig. 4), phospholipid composition (Table 6) or fatty acid composition could be observed (Table 7). The incorporation of injected labelled ethanolamine into brain lipids ( $<0.01 \%$ of injected dose $/ \mathrm{g}$ ) was too low to permit adequate determination of the level of phospholipid methylation.

\section{Neurological examinations}

Motor nerve conduction velocity measurements showed no significant difference between the groups. At 1 week before slaughter the mean $( \pm \mathrm{SE})$ velocity $(\mathrm{m} / \mathrm{s})$ for the folate-deficient rats was $33 \cdot 6 \pm 3 \cdot 4(n 5)$ and for the controls $34 \cdot 9 \pm 0 \cdot 9(n 11)$. Likewise, tests of co-ordination failed to show significant differences between groups after 5 months. 
Table 6. Expt A. Phospholipid composition (\% lipid-phosphorus) in liver and brain of rats deprived of or supplemented with folate

(Mean values with their standard errors; no. of animals in parentheses)

\begin{tabular}{|c|c|c|c|c|}
\hline \multirow[t]{2}{*}{ Folate status... } & \multicolumn{2}{|c|}{ Deficient (8) } & \multicolumn{2}{|c|}{ Supplemented (12) } \\
\hline & Mean & $\mathbf{S E}$ & Mean & $\mathrm{SE}$ \\
\hline \multicolumn{5}{|l|}{ Liver } \\
\hline Ethanolamine phosphoglyceride & $32 \cdot 5^{* * *}$ & 0.5 & $28 \cdot 5$ & 0.4 \\
\hline Choline phosphoglyceride & $40 \cdot 9^{* * *}$ & 0.8 & 46.8 & 0.6 \\
\hline $\begin{array}{l}\text { Inositol phosphoglyceride }+ \\
\text { serine phosphoglyceride }+ \\
\text { sphingomyelin }\end{array}$ & $18 \cdot 7$ & 0.7 & $17 \cdot 3$ & 0.6 \\
\hline Brain & \multicolumn{2}{|c|}{ (3) } & \multicolumn{2}{|c|}{ (3) } \\
\hline Ethanolamine phosphoglyceride & 37.4 & 1.2 & $36 \cdot 7$ & $1 \cdot 0$ \\
\hline Choline phosphoglyceride & 33.9 & 1.0 & $34 \cdot 1$ & $1 \cdot 3$ \\
\hline $\begin{array}{l}\text { Inositol phosphoglyceride + } \\
\text { serine phosphoglyceride+ } \\
\text { sphingomyelin }\end{array}$ & $19 \cdot 7$ & 0.6 & $20 \cdot 9$ & 0.6 \\
\hline
\end{tabular}

Statistical significance of difference between groups $(t$ test $): * * P<0.001$.

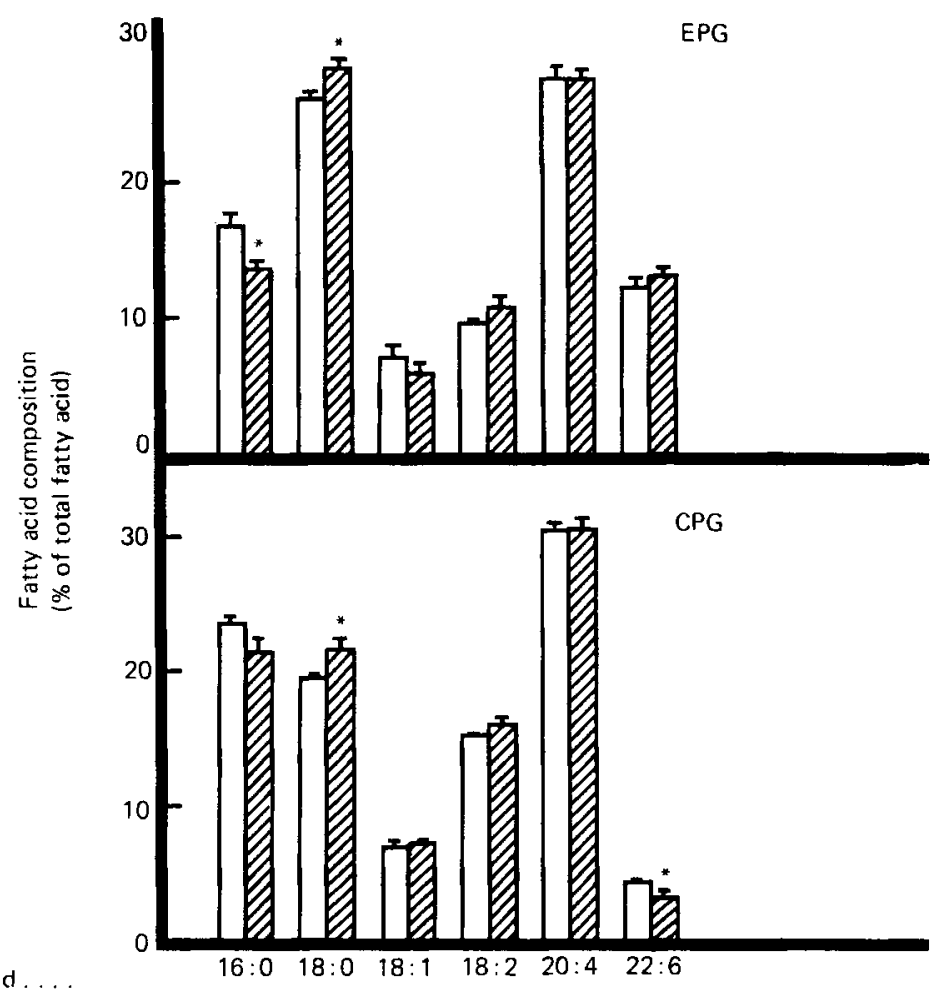

Fatty acid.

Fig. 6. Expt. A. Composition of fatty acids (\% total fatty acids) in liver phospholipids of folate-deficient (诸) or supplemented $(\square)$ rats. Values are means with their standard errors represented by vertical bars for three to four rats. EPG, ethanolamine phosphoglyceride; CPG, choline phosphoglyceride. The difference between groups was statistically significantly different: ${ }^{*} P<0.05$. 
Table 7. Expt A. Fatty acid composition (\% total brain fatty acids) of folate-deficient and supplemented rats

(Mean values with their standard errors; no. of animals in parentheses)

\begin{tabular}{|c|c|c|c|c|}
\hline \multirow{2}{*}{$\begin{array}{l}\text { Folate status... } \\
\text { Fatty acid }\end{array}$} & \multicolumn{2}{|c|}{ Deficient (5) } & \multicolumn{2}{|c|}{ Supplemented (6) } \\
\hline & Mean & SE & Mean & SE \\
\hline $16: 0$ & $21 \cdot 2$ & 0.6 & $21 \cdot 6$ & 0.6 \\
\hline $16: 1$ & 0.7 & $0 \cdot 1$ & 0.7 & 0.1 \\
\hline $18: 0$ & $21 \cdot 6$ & $0 \cdot 3$ & $21 \cdot 6$ & $0 \cdot 3$ \\
\hline $18: 1$ & $23 \cdot 3$ & 0.3 & $23 \cdot 1$ & 0.3 \\
\hline $18: 2$ & 0.7 & 0.0 & 0.8 & 0.0 \\
\hline $18: 3+20: 0$ & 0.5 & $0 \cdot 0$ & 0.5 & 0.0 \\
\hline $20: 1$ & $2 \cdot 4$ & $0 \cdot 2$ & $2 \cdot 4$ & 0.1 \\
\hline $20: 4(n-6)$ & $10 \cdot 6^{*}$ & 0.1 & $10 \cdot 2$ & $0 \cdot 1$ \\
\hline $22: 4(n-6)$ & $3 \cdot 2$ & 0.1 & $3 \cdot 3$ & $0 \cdot 3$ \\
\hline $22: 5(n-6)$ & $1 \cdot 7^{*}$ & $0 \cdot 1$ & $1 \cdot 4$ & $0 \cdot 1$ \\
\hline $22: 5(n-3)$ & $2 \cdot 1$ & $0 \cdot 1$ & $2 \cdot 0$ & $0 \cdot 1$ \\
\hline $22: 6(n-3)$ & $11 \cdot 9^{*}$ & $0 \cdot 1$ & $12 \cdot 6$ & $0 \cdot 2$ \\
\hline
\end{tabular}

Statistical significance of difference between groups $(t$ test $): P<0.05$.

\section{Liver morphology}

Four folate-deficient livers in both experiments showed a yellow colour change at autopsy indicating lipid infiltration. One of the livers in the supplemented-deficient group showed a less conspicuous change in the same direction. Such yellow metamorphosis was never seen in the folate-supplemented animals.

By light microscopy the control rats showed normal livers except for small fat vacuoles in the centro-lobular parenchymal cells in some of the rats. The most pronounced changes encountered are demonstrated in Plate 1(1).

The folate-deficient rats revealed marked changes (Plate 1(2)). There was often a considerable amount of bile ductular cells in the lobuli, which were, however, preserved, and there was no cirrhosis. Liver parenchymal cells and their cytoplasm, nuclei and nucleoli were often larger than normal. Fat vacuoles of varying number and size, larger than in control rats were encountered in parenchymal cells all over the lobules.

The ultrastructural examination confirmed the normal appearance of the control livers with few lysosomes and a moderate number of free polysomes. The rough-surfaced endoplasmic membranes were also found in stacks. The cells were rich in mitochondria. Nuclei and nucleoli were of normal appearance.

The enlarged parenchymal cells in the deficient rats had large nuclei with often indented nuclear membranes (Plate 2). The enlarged nucleoli had a normal structure. The mitochondria were occasionally swollen but generally normal in appearance. Free polysomes showed no changes. The rough-surfaced endoplasmic reticulum appeared to be decreased and the membranes did not occur in stacks. Fat vacuoles were present in various size and numbers. Slightly increased numbers of lysosomes were encountered in a few cells.

\section{DISCUSSION}

The dietary intake of choline, methionine, folate and vitamin $B_{12}$ influences the supply and transfer of methyl groups and other $\mathrm{C}-1$ groups. Dietary deficiency of each component gives rise to specific deficiency syndromes but due to the metabolic interrelationships some derangements may be common for several of the deficiencies, at least at the biochemical level. In addition, the dietary requirements for one of the so-called lipotropic factors can be dependent on the intake of other lipotropes. 


\section{Experimental folate deficiency}

The lowest folate concentrations, reflected mainly by liver values, were recorded in Expt A despite its shorter duration. This was probably due to the supplementation with folate after 5 months to the most folate-deficient animals in Expt B, leaving the less deficient rats to represent the folate-deprived group in the final analysis. A period of 8 weeks folate supplementation was not sufficient for the most folate-deprived rats to catch up with the animals that had been supplemented from the beginning (Table 1). Surprisingly, cerebrospinal fluid folate, thought to be slow to react to the oral administration of folate in man (Alperin \& Haggard, 1970; Shaw et al. 1971) was the only factor that was normalized after supplementation. Cerebrospinal fluid folate was higher than serum folate in analogy with conditions in man, contrasting with previous findings in the rat (Fehling et al. 1978). This was due to exceptionally low serum folate levels in the present experiment.

Folate levels were generally low as compared to an earlier experiment in our laboratory (Fehling et al. 1976). This can be ascribed to the addition of succinylsulphathiazole to the diet, and to the use of wire-mesh bottoms in the cages, minimizing coprophagy. The role of succinylsulphathiazole was further examined by analysis of sulphonamides in tissues. The absorption of sulphathiazole from the 'insoluble' compound was found to be amazingly large as reflected by levels of sulphonamides in serum, sometimes comparable to therapeutic levels in man. It was ascertained that these high levels did not interfere with the microbiological assays.

Addition to the feed of an intestinal disinfectant is a standard procedure in experiments designed to induce vitamin deficiency. The usual dose of sulphonamide is at least twice that used in the present experiment (see e.g. Ordonez \& Wurtman, 1974) yet we failed to find any previous report of concentrations of sulphonamide in blood or tissues. Too high concentrations are known to be toxic to the rat (Kodicek \& Carpenter, 1950a). Whether sulphonamides in the liver interfere with lipid metabolism or liver cell morphology is not known.

Although folate levels were very low in the rats given the deficient diet and vitamin $B_{12}$ concentrations were also relatively low, no severe anaemia could be demonstrated. This is contrary to the findings of Kodicek \& Carpenter $(1950 \mathrm{~b})$, but these authors used twice the concentration of dietary sulphonamide employed by us. The anaemia could not be adequately classified in our experiment as erythrocyte counts were not made. The mean corpuscular haemoglobin concentration $(\mathrm{g} / \mathrm{l})$ averaged 317 in the folate-deficient rats and 337 in the supplemented group, indicating a hypochromic anaemia in folate deficiency.

Deficiency of vitamin $B_{12}$ can give rise to changes of the structure and function of the brain, the spinal cord and the peripheral nerves in man. Folate deficiency, too, has lately been implicated as a possible cause of encephalopathy, myelopathy and polyneuropathy (reviewed by Melamed, 1979).

We have previously demonstrated neurological impairment (Fehling et al. 1978) and abnormalities of lipid composition in nervous tissue of vitamin $\mathbf{B}_{12}$-deficient rats ( $\AA$ kesson et al. 1979). In the present study we hoped to make similar findings in experimental folate deficiency. The basis for this was the metabolic relationship between 5-methyltetrahydrofolic acid and vitamin $B_{12}$ in methylating reactions, mediated by S-adenosylmethionine. The lack of abnormalities in the function and lipid composition of the central nervous system could be due to the resistance to folate depletion shown by this tissue in the present and previous studies (Fehling et al. 1976). However, the function of the peripheral nerves, where the folate depletion was as severe as in non-nervous tissue, was intact too. 


\section{Relation of folate deficiency to other lipotropic nutrients}

The supplementation of the diet with $10 \mu \mathrm{g}$ cyanocobalamin $/ \mathrm{kg}$ was not sufficient to keep a stable level of vitamin $B_{12}$ in growing rats in the presence of succinylsulphathiazole. The lower values of vitamin $B_{12}$ in the folate-deprived rats could be due to the folate deficiency possibly interfering with vitamin $B_{12}$ absorption (Forshaw, 1969; Scott et al. 1969) or to their smaller intake of feed. However, the vitamin $B_{12}$ levels were not as low as in experiments designed to induce vitamin $B_{12}$ deficiency (Fehling et al. 1978) except in the folate-supplemented deficient group. The fact that no odd-chain fatty acids accumulated in tissue lipid argues against the possibility that the animals had developed vitamin $\mathbf{B}_{12}$ deficiency (Garton et al. 1975; Fehling et al. 1978).

The relative liver weight was increased in folate deficiency, and according to the gross and microscopical appearance and the chemical analysis lipid had accumulated in the liver. Obviously, the present diet containing $(\mathrm{g} / \mathrm{kg}) 0.5$ choline, 6.7 methionine, and being supplemented with vitamin $\mathbf{B}_{12}$ but not with folic acid may be deficient in lipotropic agents. Fatty infiltration of the liver has been most extensively studied in choline-methionine deficiency (Lucas \& Ridout, 1967), and the dietary requirement of choline for preventing both kidney lesions and fatty liver is between 0.5 and $1.0 \mathrm{~g} / \mathrm{kg}$ diet. Furthermore, it has been demonstrated that a methionine level of $8 \mathrm{~g} / \mathrm{kg}$ diet prevents kidney lesions that are due to choline deficiency. Hale \& Schaefer (1951) found the requirements of choline to be decreased by dietary vitamin $B_{12}$ and folic acid. Also Laird et al. (1965) found folic acid to be lipotropic, when combined with vitamin $B_{12}$ and choline, although an excess of folic acid was not lipotropic alone if tested on animals on a high-fat diet. It appears from our experiment, where the animals were not overloaded with dietary fat, that folic acid per se has a lipotropic effect, or rather that folate deprivation could give rise to liver steatosis if the supply of vitamin $B_{12}$ and choline is limited. This could be relevant for the fatty infiltration of liver, seen in alcoholics who are prone to become deficient in folic acid (Halsted \& Tamura, 1979) and also have a low intake or absorption of other nutrients or both.

\section{Phospholipid metabolism}

Phospholipid methylation in liver has been studied extensively in animals with methioninecholine deficiency. In vitro measurement showed that the methylating activity from AdoMet increased in choline deficiency (Fallon et al. 1969; Glenn \& Austin, 1971; Schneider \& Vance, 1978). The conversion in vivo of liver EPG to CPG was, however, decreased (Lyman et al. 1973). These seemingly contradictory findings can be explained by the pattern of substrate concentration changes recently proposed for the isolated hepatocyte model ( $\AA$ kesson, 1980). The increase in EPG as in choline deficiency (Haines \& Rose, 1970; Lyman et al. 1973), in vitamin $B_{12}$ deficiency ( $\AA$ kesson et al. 1978; Ákesson et al. 1979) and also in folate deficiency (Table 6) will increase the methylation rate both when measured in intact cells and in subcellular fractions ( $\AA$ kesson, 1978). Further support for the role of EPG availability was obtained in experiments where the concentration of EPG in liver microsomes was varied by treatment with amino-group-blocking agents ( $\AA$ kesson, unpublished results).

The depressed phospholipid methylation in vivo in folate deficiency (Table 5) and choline deficiency, in spite of the increase in EPG, can be ascribed to a decreased availability of AdoMet or methionine or both. In fact, AdoMet in liver and also in the brain is decreased in folate deficiency (Ordonez \& Wurtman, 1974). The activity of tetrahydropteroyl-glutamate methyltransferase $(E C 2.1 .1 .10)$ in liver is essentially unchanged, and therefore, the decrease in AdoMet may be the consequence of the lower availability of methyltetrahydrofolate (Ordonez \& Wurtman, 1974). The role of inhibitors of phospholipid methylation such as S-adenosylhomocysteine (Hoffman et al. 1979) cannot be assessed at present. 
Phospholipid methylation is most active in the liver although it also occurs in other organs. Recently Hirata \& Axelrod (1980) have postulated that this reaction is related to biological signal transmission in different cells. Whether such processes are influenced by the dietary supply of lipotropic factors remains an area for future research.

In addition to the changes in EPG methylation, de novo synthesis of EPG was affected in folate deficiency (Table 4, Fig. 5). Labelled phosphoethanolamine accumulated indicating a decreased conversion of this compound to EPG via CDP-ethanolamine. Although changes in conversion rate cannot be calculated since the pool sizes are not known, the large differences in phosphoethanolamine and EPG radioactivity (Fig. 5) indicate a real decrease in the conversion in folate deficiency. This decrease is probably controlled at the CTP: ethanolaminephosphate cytidylyltransferase step $(E C 2.7 .7 .14)$ which is the major rate-limiting reaction in EPG biosynthesis (Sundler \& Åkesson, 1975).

An impairment at the CTP: ethanolaminephosphate cytidylyltransferase step has been found also in choline deficiency (Haines \& Rose, 1970; Tokmakjian \& Haines, 1979). The mechanism of the inhibition may be a change in the CTP:CDPethanolamine value (Sundler, 1975), but the cause of such a change is unknown. We suggest that the impaired EPG methylation, which normally accounts for the turnover of a substantial proportion of liver EPG ( $\AA$ kesson \& Sundler, 1977), is the primary change in EPG metabolism in folate deficiency. The impaired methylation or the increased amount of EPG or both probably also leads to the accumulation of water-soluble precursors of EPG.

\section{Fatty acid composition}

Folate deficiency caused only few changes in fatty acid composition of liver phospholipids and brain lipids. The increase of stearate in liver phospholipids is analogous to that found in choline-methionine deficiency (Lyman et al. 1971, 1973), but in these studies palmitate also was increased, in contrast to our findings (Fig. 6). The decrease in docosahexaenoate in liver CPG may reflect the impaired conversion of hexaenoic EPG to CPG, but other mechanisms may also be operating since in choline-methionine deficiency varying changes in CPG docosahexaenoate in liver have been observed (Beare-Rogers, 1971 ; Lyman et al. 1971, 1973). Neither has a consistent pattern of fatty acid changes been observed in vitamin $B_{12}$ deficiency, except for the accumulation of odd-chain fatty acids (Fehling et al. 1978; Åkesson et al. 1979; Peifer \& Lewis, 1979). No increase in odd-chain fatty acids was found in folate deficiency in this study. Hirono \& Wada (1978) found a decrease in docosahexaenoate in myelin from brains of 6-week-old folate-deficient rats but no change in arachidonate. No major changes in brain fatty acid composition were observed in the present study (Table 7).

\section{Morphology of liver}

Folic acid deficiency has not previously been described to give changes in liver parenchymal cells. However, the folic acid antagonist methotrexate causes fatty liver and areas of hepatocytic polyploidy or anisonucleosis and enlarged liver cells in man and the rat (Roenigk et al. 1971; Shapiro et al. 1974; Nesbit et al. 1976; Custer et al. 1977) and possibly mitochondrial enlargement (Shapiro et al. 1974), alterations that are all similar to those found by us.

The changes found in the livers of the folic acid-deficient rats were very similar or identical to those observed by electron microscopy in choline deficiency. The nuclear and nucleolar alterations (Grisham et al. 1960) as well as the increase in intralobular ductular cells (Grisham \& Hartroft, 1961) are considered to be a stage in the development of cirrhosis.

The enlarged nucleoli and the apparent decrease in rough-surfaced endoplasmic reticulum suggest an altered RNA metabolism. Haltia (1970) found a decreased content of RNA in cerebellar cells of 4-week-old chicks, given a folate-deficient diet since birth. In our 
experiment the low levels of total folate suggest proportionately low concentrations of formyltetrahydrofolate and methylidynetetrahydrofolate which are both necessary for the formation of the purine rings of RNA.

This investigation was supported by grants from the Swedish Medical Research Council (Project 3968) the Faculty of Medicine, University of Lund, A. Påhlsson's Foundation, The Swedish Multiple Sclerosis Society and the Margaretahemmet Foundation. Skilful technical assistance was provided by Ms K. Kvist, Mrs A.-K. Westesson and Mr J. Wijkander. Sulphonamide concentrations were determined by the courtesy of Dr A. Hanson(Department of Clinical Chemistry, Section of Toxicology, General Hospital of Malmö).

\section{REFERENCES}

Åkesson, B. (1978). FEBS Lett. 92, 177.

Åkesson, B. (1980). In Membrane Fluidity: Biophysical Techniques and Cellular Regulation, p. 419 [M. Kates and A. Kuksis, editor]. Clifton, N.J.: The Humana Press.

Åkesson, B., Fehling, C. \& Jägerstad, M. (1978). Br. J. Nutr. 40, 521.

Åkesson, B., Fehling, C. \& Jägerstad, M. (1979). Br. J. Nutr. 41, 263.

Åkesson, B. \& Sundler, R. (1977). Biochem. Soc. Trans. 5, 43.

Alperin, J. B. \& Haggard, M. E. (1970). Clin. Res. 18, 40.

Annino, J. S. (1961). In Standard Methods of Clinical Chemistry, vol. 3, p. 200 [D. Seligson, editor]. New York: Academic Press.

Beare-Rogers, J. L. (1971). Lipids 6, 649.

Crews, F. T., Hirata, F. \& Axelrod, J. (1980). J. Neurochem. 34, 1491.

Custer, R. P., Freeman-Narrod, M. \& Narrod, S. A. (1977). J. natn. Cancer Inst. 58, 1011.

Fallon, H. J., Gertman, P. M. \& Kemp, E. L. (1969). Biochim. biophys. Acta 187, 94.

Fehling, C., Abdulla, M., Brun, A., Dictor, M., Schütz, A. \& Skerfving, S. (1975). Toxic. appl. Pharmac. 33, 27.

Fehling, C. \& Jägerstad, M. (1978). Nutr. Metab. 22, 90.

Fehling, C. \& Jägerstad, M. (1979). In Folic Acid in Neurology, Psychiatry, and Internal Medicine, p. 517 [M. I. Botez and E. H. Reynolds, editors]. New York: Raven Press.

Fehling, C., Jägerstad, M., Akesson, B., Axelsson, J. \& Brun, A. (1978). Br. J. Nutr. 39, 501.

Fehling, C., Jägerstad, M., Lindstrand, K. \& Elmquist, D. (1976). Z. Ernährungswiss 15, 1.

Forshaw, A. J. (1969). J. clin. Path. 22, 551.

Garton, G. H., Scaife, J. R., Smith, A. \& Siddons, R. C. (1975). Lipids 10, 855.

Glenn, J. L. \& Austin, W. (1971). Biochim. biophys. Acta 231, 153.

Grisham, J. W., Banson, B. B. \& Hartroft, W. S. (1960). Archs Path. 70, 50.

Grisham, J. W. \& Hartroft, W. S. (1961). Lab. Invest. 10, 317.

Haines, D. S. M. \& Rose, C. I. (1970). Can. J. Biochem. $48,885$.

Hale, O. M. \& Schaefer, A. E. (1951). Proc. Soc. exp. Biol. Med. 77, 633.

Halsted, C. H. \& Tamura, T. (1979). In Problems in Liver Disease, p. 91 [C. S. Davidson and H. M. Stratton, editors]. New York: Academic Press.

Haltia, M. (1970). Br. J. exp. Path. 51, 191.

Hirata, F. \& Axelrod, J. (1980). Science, N.Y. 209, 1082.

Hirono, H. \& Wada, Y. (1978). J. Nutr. 108, 766.

Hoffman, D. R., Cornatzer, W. E. \& Duerre, J. A. (1979). Can. J. Biochem. 57, 56.

Jägerstad, M., Åkesson, B. \& Fehling, C. (1980). Br. J. Nutr. 44, 361.

Kodicek, E. \& Carpenter, K. J. (1950a). Blood 5, 540.

Kodicek, E. \& Carpenter, K. J. (1950b). Blood 5, 522.

Laird, R. D., McCormick, H. M. \& Drill, V. A. (1965). Toxic. appl. Pharmac. 7, 247.

Lucas, C. C. \& Ridout, J. H. (1967). Progr. Chem. Fats Other Lipids 10, 1.

Lyman, R. L., Sheehan, G. \& Tinoco, J. (1971). Can. J. Biochem. 49, 71.

Lyman, R. L., Sheehan, G. \& Tinoco, J. (1973). Lipids 8, 71.

Melamed, E. (1979). In Folic Acid in Neurology, Psychiatry, and Internal Medicine, p. 423 [M. I. Botez and E. H. Reynolds, editors]. New York: Raven Press.

Nesbit, M., Krivit, W., Heyn, R. \& Sharp, H. (1976). Cancer 37, 1048.

Ordonez, L. A. \& Wurtman, R. J. (1974). Archs Biochem. Biophys. 160, 372.

Peifer, J. J. \& Lewis, R. D. (1979). J. Nutr. 109, 2160.

Roenigk, H. H., Bergfeld, W. F., Jaques, R. St., Owens, F. J. \& Hawk, W. A. (1971). Archs Derm. 103, 250.

Schneider, W. J. \& Vance, D. E. (1978). Eur. J. Biochem. 85, 181.

Scott, R. B., Kammer, R. B., Burger, W. \& Middleton, F. G. (1969). Anns Int. Med. 69, 111.

Shapiro, H. A., Trowbridge, J. O., Lee, J. C. \& Mairbach, H. I. (1974). Archs Derm. 110, 551. 
Shaw, D. M., Macsweeney, D. A., Johnson, A. L., O'Keefe, R., Naidoo, D., MacLeod, D. M., Jog, S., Preece, J. M. \& Crowley, J. M. (1971). Psychol. Med. 1, 166.

Sipos, J. C. \& Ackman, R. G. (1978). J. Chrom. Sci. 16, 443.

Sundler, R. (1973). Biochim. biophys. Acta. 306, 218.

Sundler, R. (1975). J. biol. Chem. 250, 8585.

Sundler, R. \& Åkesson, B. (1975). J. biol. Chem. 250, 3359.

Sundler, R., Arvidson, G. \& Åkesson, B. (1972). Biochim. Biophys. Acta 280, 559.

Tokmakjian, S. \& Haines, D. S. M. (1979). Can. J. Biochem. 57, 566.

\section{EXPLANATION OF PLATES}

\section{Plate 1}

(1) Light microscope section of folate-supplemented rat liver. There are a few vacuoles in the parenchymal cells in the central part of the lobulus in the lower left corner of the picture. (Stain, hematoxylin-erythrosine; $\times 275$ ). (2) Light microscope section of folic acid-deficient rat. Liver parenchymal cells and their nuclei and nucleoli vary in size and are often conspicuously enlarged. The parenchymal cells contain fat vacuoles in varying number. Several intralobular ductular cells are found. (Stain, hematoxylin-erythrosine; $\times 275$ ).

\section{Plate 2}

Electronmicroscope section of liver of folic acid-deficient rat. The cell nucleus is enlarged and its surface indented. The enlarged nucleoli have a normal substructure. In the cytoplasm there are a few fat vacuoles. The rough-surfaced endoplasmic reticulum does not occur in stacks. The mitochondria are normal. (Stain, uranyl acetate-lead citrate; $\times 13000$ ). 


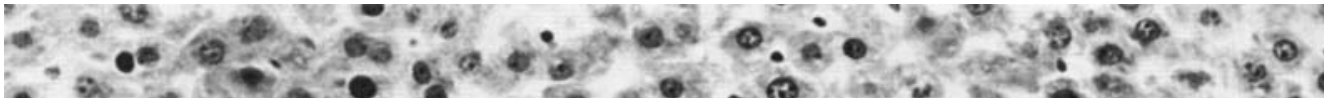

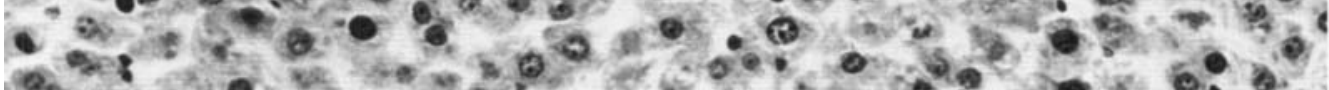

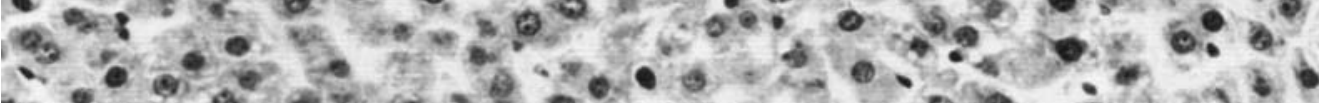

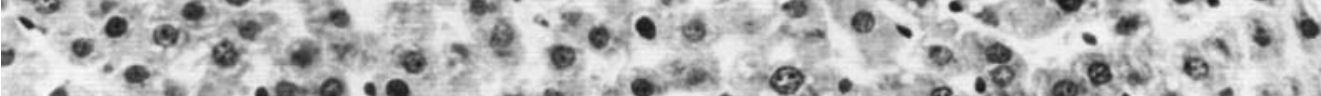

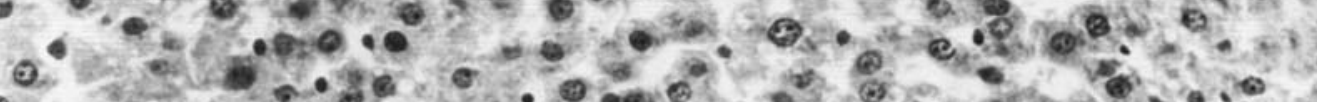

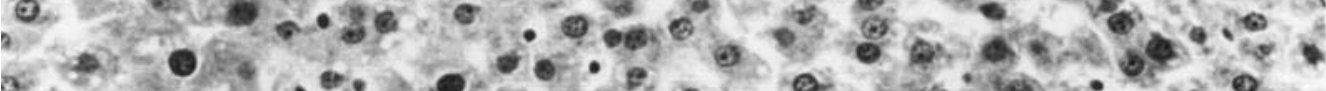

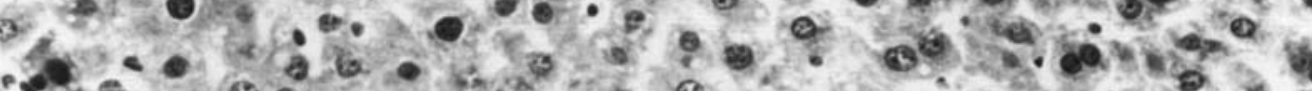

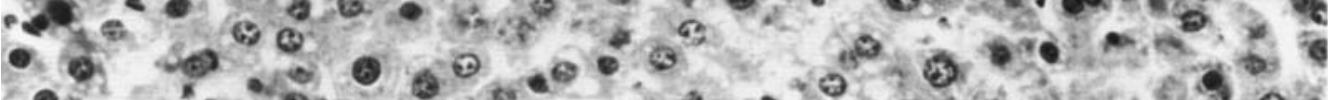
- H.

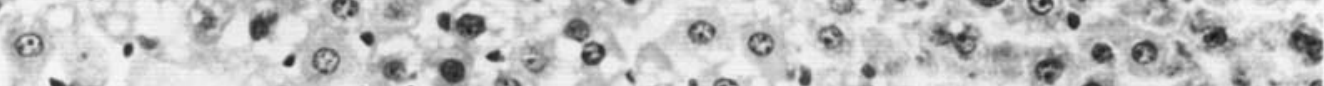

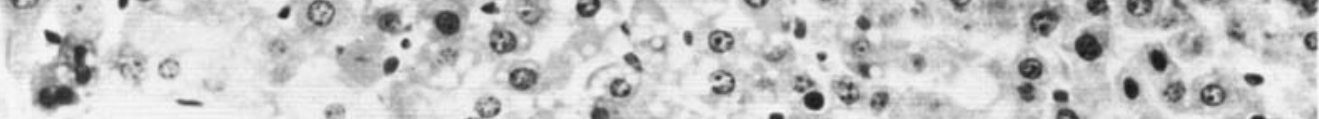

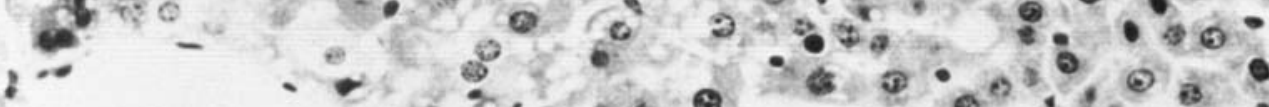

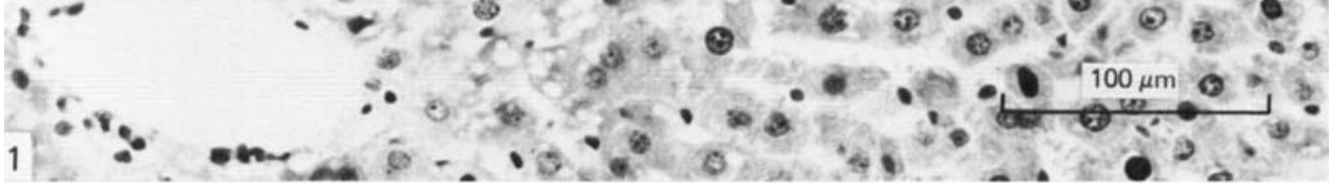

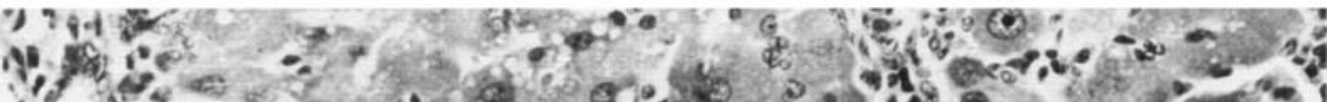

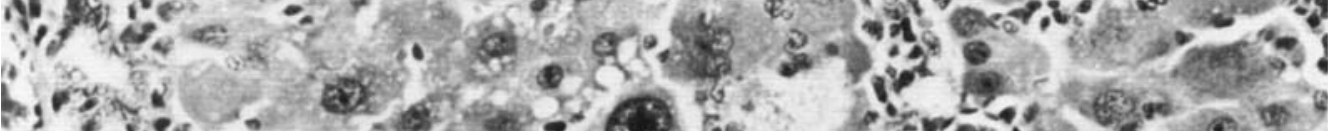

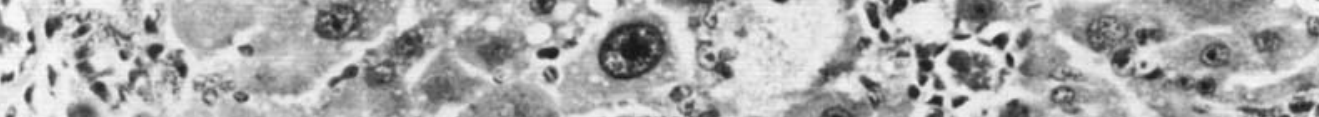

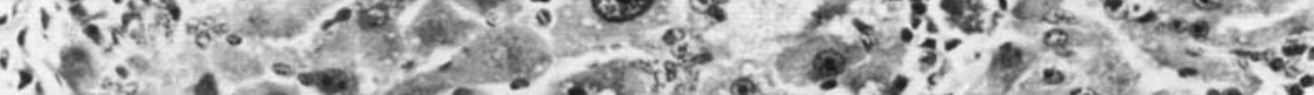

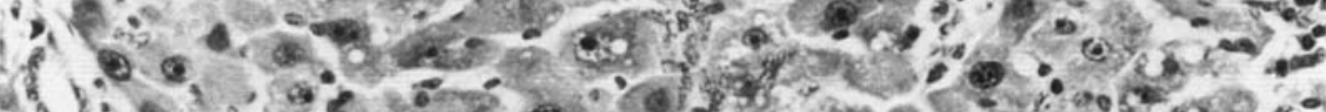

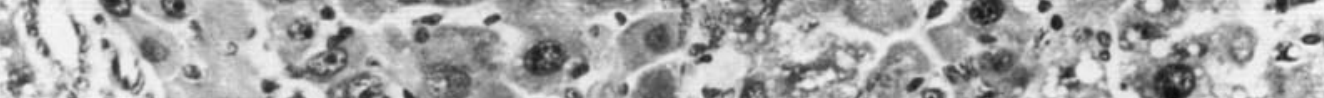

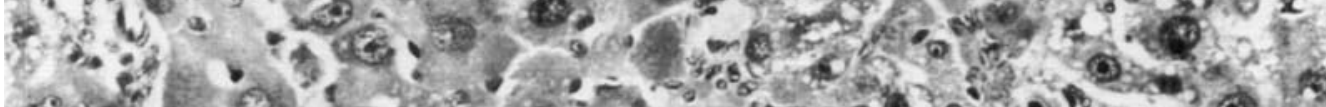

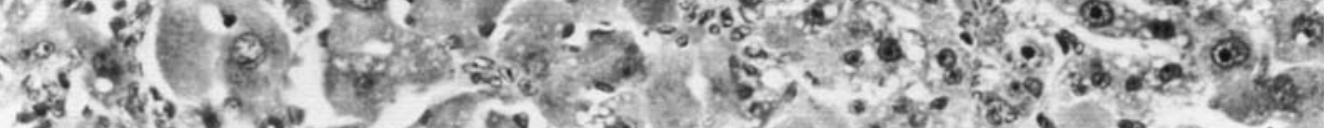

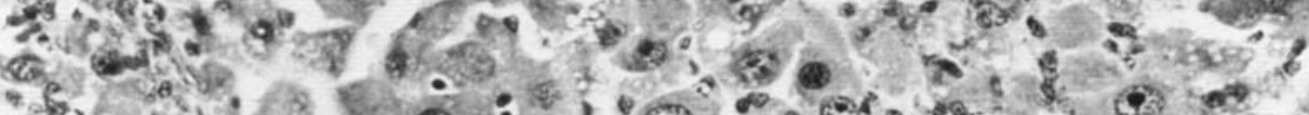

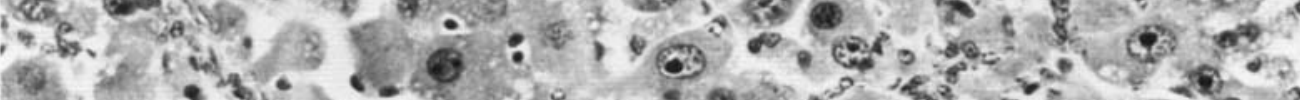

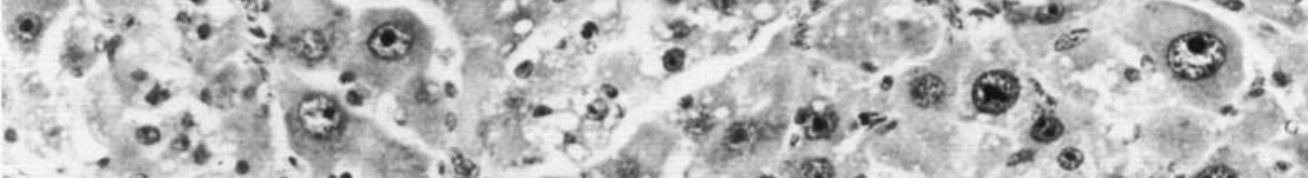

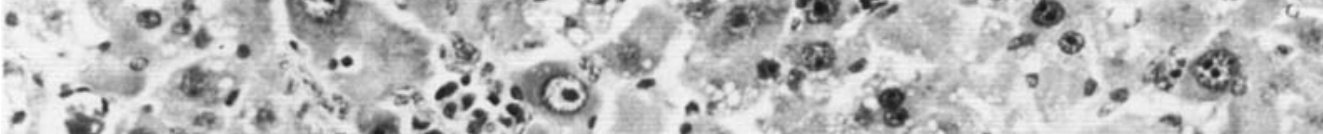

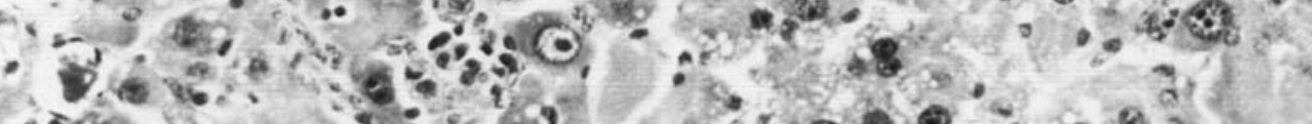

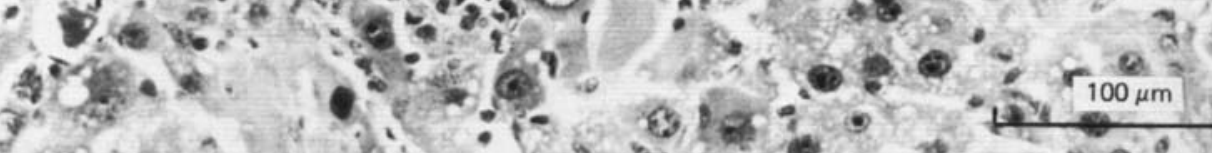

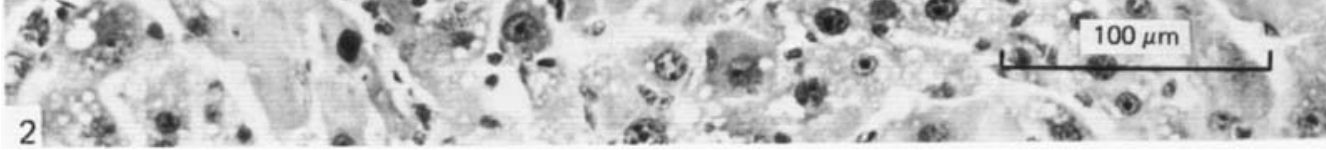




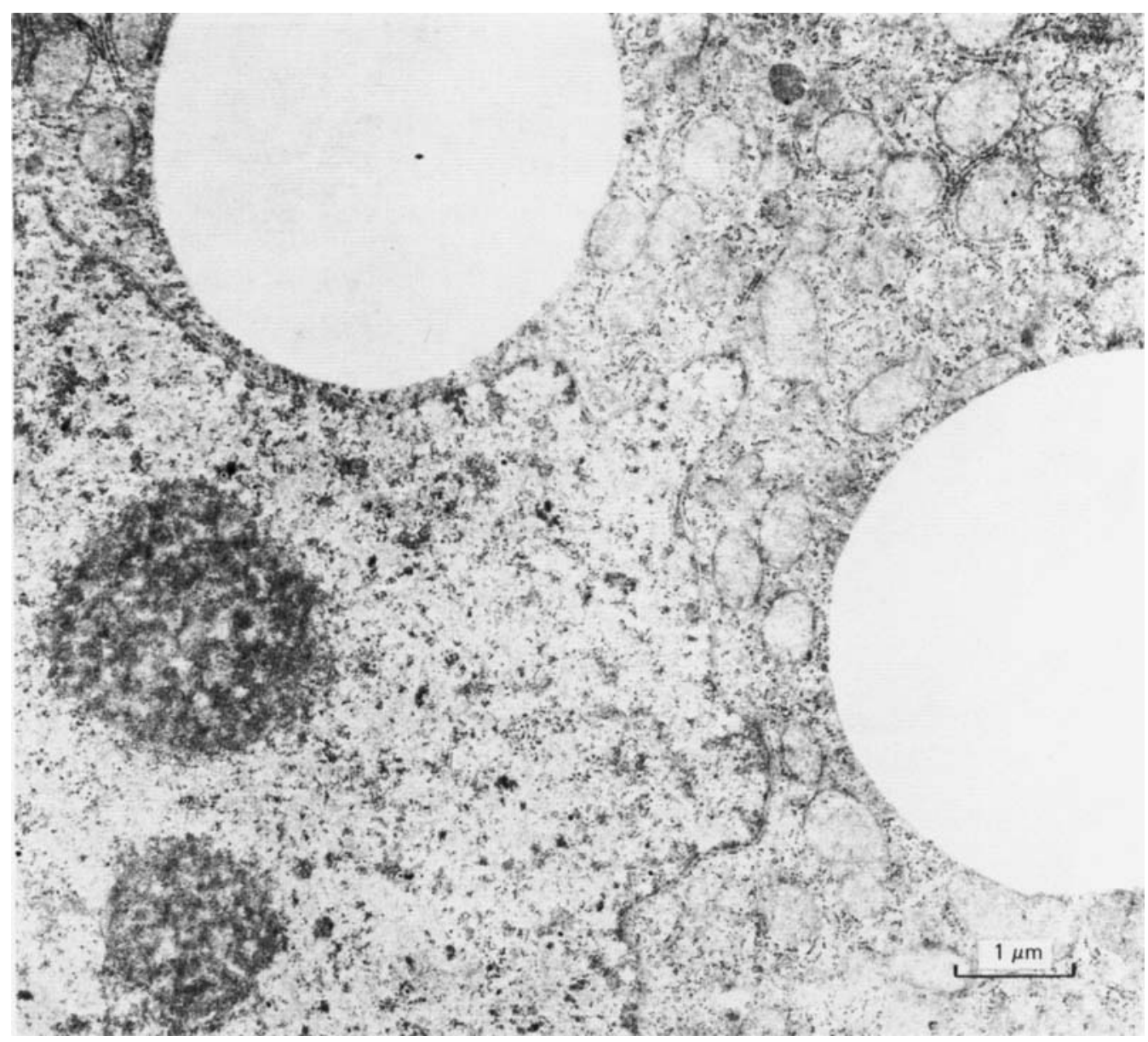

B. ÁKESSON AND OTHERS 